\title{
Complexes of iron and cobalt with new tripodal amido-polyphosphine hybrid ligands $\uparrow$
}

\author{
Matthew T. Whited, Eric Rivard and Jonas C. Peters* \\ Received (in Berkeley, CA, USA) 14th November 2005, Accepted 1st March 2006 \\ First published as an Advance Article on the web 10th March 2006 \\ DOI: 10.1039/b516046d
}

Divalent complexes of iron and cobalt with new, monoanionic tripodal amido-polyphosphine ligands have been thoroughly characterized, and XRD analysis reveals geometries that are distinct for this class of ligand.

Rational ligand design has figured prominently in the discovery of metal complexes with novel properties, and changes in ligand scaffolds can be utilized to tune reactivity both by the choice of donors and the geometry conferred about the metal center. Our group has been examining tris(phosphino)borate ligands that educe interesting reactivity patterns from iron and cobalt with various substrates, helping to stabilize a range of oxidation states. For example, complexes of iron and cobalt with tris(phosphino)borate ligands show a propensity to coordinate and stabilize multiply-bonded ligand moieties, ${ }^{1}$ and cobalt complexes supported by these ligands have revealed a number of unexpected electronic properties due to the strong field and distorted tetrahedral geometry conferred by the ligand. ${ }^{2,3}$ In this context, we were eager to consider analogues of the (phosphino)borates in which the negative charge would be carried by an X-type donor ligand rather than the borate backbone.

Particularly interesting to us were the mixed amide-phosphine hybrid ligands first developed by Fryzuk and coworkers. ${ }^{4,5}$ As Fryzuk has noted, these scaffolds combine "hard" amido and "soft" phosphine donors, allowing them to bind many transition metals, stabilize a variety of oxidation states, and induce interesting transformations. ${ }^{6}$ Several properties of these hybrid ligands were appealing to us. First, the amido donor bears the uninegative charge rather than a borate unit. We also anticipated that amidopolyphosphines would be electron-releasing, like their poly(phosphino)borate analogues, but with the distinction that the lone pair at the amido substituent would be available for $\pi$-donation. Such ligands should likewise support low- and mid-valent group transfer reactions, though it is likely that the potential for $\pi$-donation from the amide will alter the reactivity of other multiply-bonded ligands. While the chemistry of iron and cobalt amide-phosphine complexes is limited in scope, ${ }^{7,8}$ these general types of hybrid ligands have been productively used on second- and third-row late transition metals. ${ }^{9}$

We report synthetic protocols for the preparation of the two new amido-polyphosphine ligands outlined in Scheme 1. Syntheses of the potentially tetradentate $\left[{ }^{\mathrm{Si}} \mathrm{NP}_{3}\right]$ ligand, an anionic relative to

Division of Chemistry and Chemical Engineering, Arnold and Mabel Beckman Laboratories of Chemical Synthesis, California Institute of Technology, Pasadena, California, 91125, USA.

E-mail: jpeters@caltech.edu; Fax: +1 6265774088; Tel: +1 6263954036 $\dagger$ Electronic supplementary information (ESI) available: Synthetic protocols and characterization data; crystallographic data. See DOI: 10.1039/ b516046d

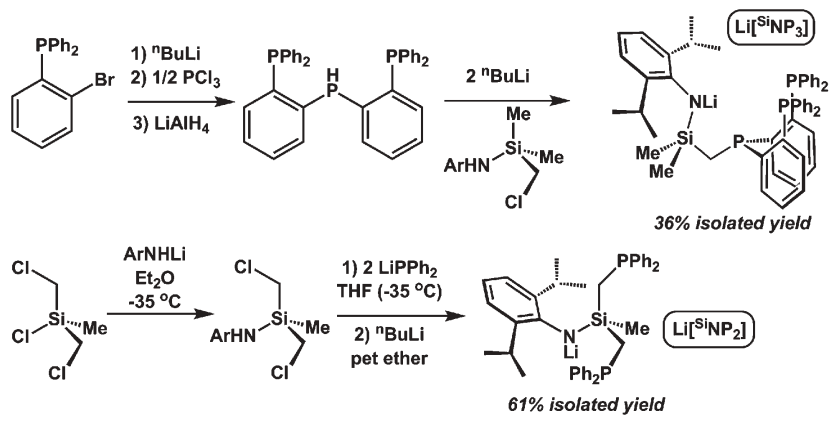

Scheme 1 Syntheses of $\left[{ }^{\mathrm{Si}} \mathrm{NP}_{2}\right]$ and $\left[{ }^{\mathrm{Si}} \mathrm{NP}_{3}\right](\mathrm{Ar}=2$,6-diisopropylphenyl $)$.

Sacconi's tris(phosphino)amine ligands, ${ }^{10}$ and of the tridentate $\left[{ }^{\mathrm{Si}} \mathrm{NP}_{2}\right]$ ligand, are straightforward and modular. Reaction of $\mathrm{Li}\left[{ }^{\mathrm{Si}} \mathrm{NP}_{3}\right]$ with $\mathrm{FeCl}_{2}$ in THF afforded $\left[{ }^{\mathrm{Si}} \mathrm{NP} \mathrm{P}_{3}\right] \mathrm{FeCl}$ (1) as a yellowbrown powder in $64 \%$ isolated yield. We were surprised to find that the complex possessed a high spin electronic configuration at $25{ }^{\circ} \mathrm{C}$ in $\mathrm{C}_{6} \mathrm{D}_{6}$ solution $\left(\mu_{\mathrm{eff}}=4.6 \mu_{\mathrm{B}}\right)$ and in the solid state (SQUID; $10 \mathrm{~K}-300 \mathrm{~K}$ ), indicative of a tetrahedral ferrous ion, ${ }^{11}$ rather than the intermediate $S=1$ state predicted for a fivecoordinate $\mathrm{Fe}$ (II) complex. The high spin formulation was consistent with the presence of highly shifted peaks in the ${ }^{1} \mathrm{H}$ NMR spectrum, from $\delta 50.8 \mathrm{ppm}$ to $-49.1 \mathrm{ppm}$. To obtain a solid-state molecular structure, compound $\mathbf{1}$ was crystallized as light yellow plates by vapor diffusion of petroleum ether into a concentrated benzene solution. XRD analysis established a pseudotetrahedral complex with one unbound phosphine arm (Fig. 1a) \$ However, it appears that this 4-coordinate structure is in equilibrium with a 5-coordinate $S=1$ species, the latter being favored at low temperature. Consistent with this idea was a color change from light yellow to dark red upon cooling a toluene solution of $\mathbf{1}$, and the corresponding appearance of two optical bands at $770 \mathrm{~nm}\left(740 \mathrm{M}^{-1} \mathrm{~cm}^{-1}\right)$ and $540 \mathrm{~nm}\left(1400 \mathrm{M}^{-1} \mathrm{~cm}^{-1}\right)$. Also, a sharp decrease in the solution magnetic susceptibility was observed upon cooling ( $\mu_{\text {eff }}=3.3 \mu_{\mathrm{B}}$ at $-66{ }^{\circ} \mathrm{C}$ in toluene- $d_{8}$ ). Electrochemical analysis of $\mathbf{1}$ revealed a reversible $\mathrm{Fe}^{\mathrm{III} / \mathrm{II}}$ couple centered at $-0.40 \mathrm{~V}$ vs. $\mathrm{Fc} / \mathrm{Fc}^{+}$, as well as irreversible waves at $-2.0 \mathrm{~V}$ and $-2.5 \mathrm{~V}$. A small wave grew in at $-1.0 \mathrm{~V}$ that appeared to be associated with the irreversible reduction event at $-2.0 \mathrm{~V}$ (Fig. 2). Chloride loss likely occurs upon reduction, followed by the formation of a new species that is oxidized at $-1.0 \mathrm{~V}$. Further synthetic and electrochemical experiments are underway to elucidate the behavior of $\mathbf{1}$ under reducing conditions.

To establish whether the $\left[{ }^{\mathrm{Si}} \mathrm{NP}_{3}\right]$ ligand might more reliably adopt the desired tetradentate binding mode, we examined its coordination to $\mathrm{Co}(\mathrm{II})$. Brick-red $\left[{ }^{\mathrm{Si}} \mathrm{NP}_{3}\right] \mathrm{CoCl}(\mathbf{2 a})$ and $\left[{ }^{\mathrm{Si}} \mathrm{NP}_{3}\right] \mathrm{CoI}$ (2b) were prepared metathetically by the reaction between 

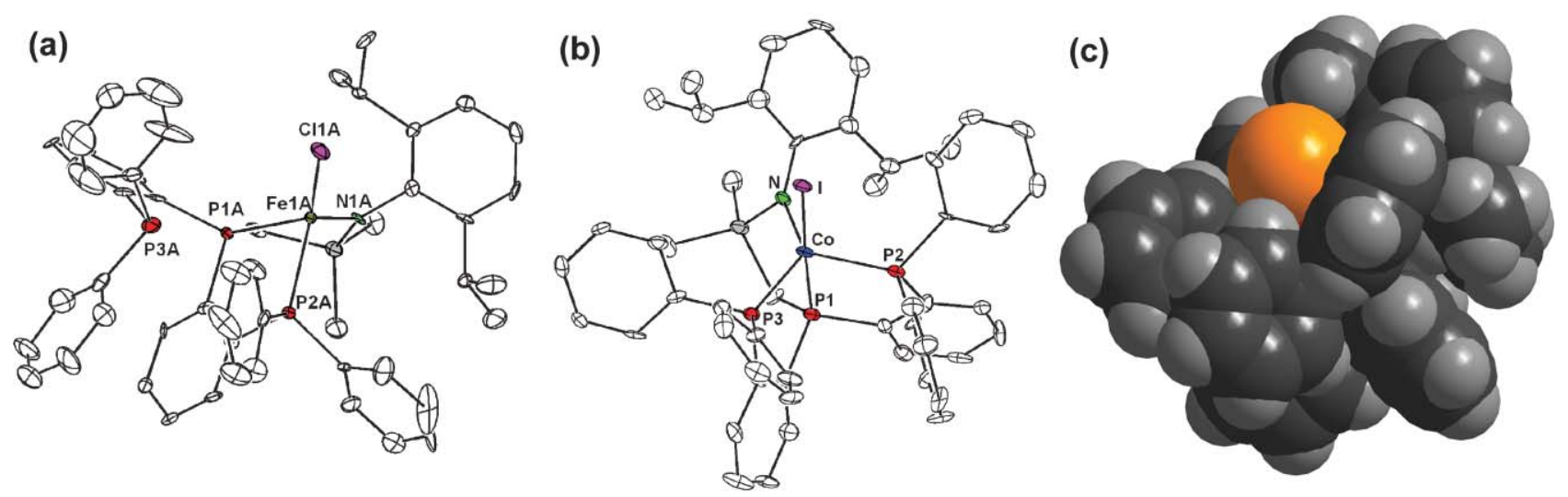

Fig. 1 Structural representations of (a) $\left[{ }^{\mathrm{Si}} \mathrm{NP}_{3}\right] \mathrm{FeCl}$ (1) and (b) $\left[{ }^{\mathrm{Si}} \mathrm{NP}_{3}\right] \mathrm{CoI}$ (2b) with thermal ellipsoids at $50 \%$ probability, and (c) a space-filling representation of $\left[{ }^{\mathrm{Si}} \mathrm{NP}_{3}\right]$ CoI. (a) Two essentially identical molecules were present in the asymmetric unit; one representative is depicted and hydrogen atoms have been omitted for clarity. This crystal suffered from appreciable disorder and several atoms were restrained to obtain a satisfactory solution (see ESI). Selected bond distances ( $(\AA)$ and angles $\left(^{\circ}\right)$ : Fe1A-N1A 1.933(9), Fe1A-P1A 2.420(3), Fe1A-P2A 2.480(3), Fe1A-P3A 3.954(6), Fe1A-Cl1A 2.242(3), N1A-Fe1A-P1A 91.0(3), N1A-Fe1A-P2A 113.8(3), P1A-Fe1A-P2A 84.1(1), N1A-Fe1A-Cl1A 121.8(3), P1A-Fe1A-Cl1A 125.9(1), P2A-Fe1A-Cl1A 113.3(1). (b) Hydrogen atoms and two solvent molecules (benzene) have been omitted for clarity. Selected bond distances $(\AA)$ and angles $\left({ }^{\circ}\right)$ : Co-N 1.990(6), Co-P1 2.139(2), Co-P2 2.260(2), Co-P3 2.250(2), Co-I 2.642(1), N-Co-P1 86.5(2), N-Co-P2 121.8(2), N-Co-P3 129.4(2), N-Co-I 101.5(2), P1Co-P2 85.81(8), P1-Co-P3 86.78(8), P1-Co-I 171.93(7), P2-Co-P3 107.57(8), P2-Co-I 89.24(6), P3-Co-I 88.66(6).

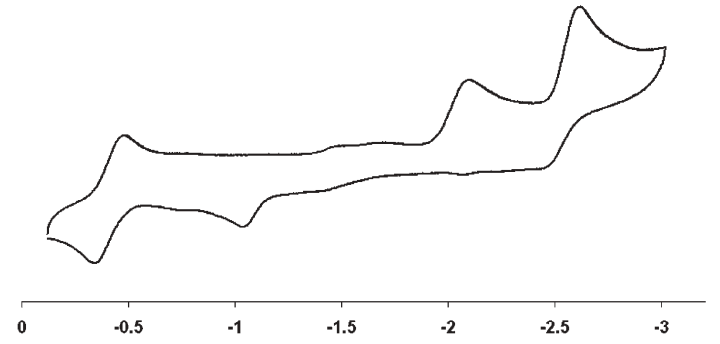

Fig. 2 Cyclic voltammetry of $\left[{ }^{\mathrm{Si}} \mathrm{NP}_{3}\right] \mathrm{FeCl}$ (1) under $\mathrm{N}_{2}$ in $0.35 \mathrm{M}$ $[\mathrm{TBA}]\left[\mathrm{PF}_{6}\right] / \mathrm{THF}$, scan rate $=250 \mathrm{mV} / \mathrm{s}, \mathrm{V}$ vs. $\mathrm{Fc} / \mathrm{Fc}^{+}$.

$\mathrm{Li}\left[{ }^{\mathrm{Si}} \mathrm{NP}_{3}\right]$ and $\mathrm{CoCl}_{2}$ or $\mathrm{CoI}_{2}$, respectively. ${ }^{12} \mathrm{X}$-ray data for crystals of low spin $2 \mathrm{a}$ ( $\mu_{\mathrm{eff}}=1.9 \mu_{\mathrm{B}}$ in $\mathrm{C}_{6} \mathrm{D}_{6}$; see ESI for X-ray data) and 2b were collected to confirm their similar structures. The structure of maroon $\mathbf{2} \mathbf{b}$ is shown in Fig. $\mathbf{1 b}$, and that of $\mathbf{2} \mathbf{a}$ is in the ESI. Complex $\mathbf{2 b}$ features a trigonal bipyramidal Co(II) center in which the iodide ligand occupies an apical position. The metal-phosphine distances in $\mathbf{2 b}$ are shorter than those found in complex $\mathbf{1}$, consistent with its low spin configuration, and the axial $\mathrm{Co}-\mathrm{P} 1$ bond is $c a$. $0.1 \AA$ shorter than the equatorial $\mathrm{Co}-\mathrm{P} 2$ and $\mathrm{Co}-\mathrm{P} 3$ bonds. The amide, $\mathrm{P} 2$, and $\mathrm{P} 3$ ligands lie in a plane that contains the cobalt center, but the $\mathrm{P} 1-\mathrm{Co}-\mathrm{I}$ axis is slightly bent (P1-Co$\mathrm{I}=172^{\circ}$ ) due to the iodide ligand being positioned away from the amide donor. A space-filling model of $\mathbf{2 b}$ (Fig. 1c) reveals an iodide ligand that is nestled within a binding pocket comprised of the phosphine phenyl substituents and a rotated diisopropylphenyl group. Canting of the 2,6-diisopropylanilide donor minimizes steric interactions between the isopropyl groups and the phenylphosphine substituents and also tilts the lone pair of the amido ligand out of the equatorial plane. The cyclic voltammetry of $\mathbf{2 a}$ resembles that of $\mathbf{1}$, featuring a reversible $\mathrm{Co}^{\mathrm{II} / \mathrm{II}}$ couple at $-0.43 \mathrm{~V}$ and an irreversible cathodic peak at $-2.1 \mathrm{~V}$. Once again, a new and irreversible anodic peak grows in at $-1.0 \mathrm{~V}$ that appears to be associated with the reduction event at $-2.1 \mathrm{~V}$ (see ESI for CV).

Unlike $\left[{ }^{\mathrm{Si}} \mathrm{NP}_{3}\right]$, the $\left[{ }^{\mathrm{Si}} \mathrm{NP}_{2}\right]$ ligand is geometrically predisposed to tridentate, facial coordination. ${ }^{13}$ This feature distinguishes it from other Fryzuk-type amide-polyphosphine ligands, for which meridional chelation dominates. ${ }^{4,7} \mathrm{Li}\left[{ }^{\mathrm{Si}} \mathrm{NP}_{2}\right]$ and $\mathrm{FeCl}_{2}$ reacted to generate $\left[{ }^{\mathrm{Si}} \mathrm{NP}_{2}\right] \mathrm{FeCl}$ (3) cleanly in $83 \%$ isolated yield. Likewise, $\left[{ }^{\mathrm{Si}} \mathrm{NP}_{2}\right] \mathrm{CoCl}(\mathbf{4 a})$ and $\left[{ }^{\mathrm{Si}} \mathrm{NP}_{2}\right] \mathrm{CoI}(\mathbf{4 b})$ could be obtained using $\mathrm{CoCl}_{2}$ and $\mathrm{CoI}_{2}$, respectively. Complex 3 is high spin $\left(\mu_{\text {eff }}=4.8 \mu_{\mathrm{B}}\right)$, consistent with the expected tetrahedral Fe(II) structure. XRD analysis of single crystals of $\mathbf{3}$ and $\mathbf{4 b}$ confirmed the tripodal binding mode of the $\left[{ }^{\mathrm{Si}} \mathrm{NP}_{2}\right]$ ligand (Fig. 3). Interestingly, the $\mathrm{N}-$ $\mathrm{Fe}-\mathrm{P}$ and $\mathrm{P}-\mathrm{Fe}-\mathrm{P}$ angles in both $\mathbf{3}$ and $\mathbf{4 b}$ are much closer to $90^{\circ}$ than we had anticipated, providing structures distinct from those of typical tetrahedra. In this regard, the $\left[{ }^{\mathrm{Si}} \mathrm{NP}_{2}\right]$ donors are better described as occupying three corners of an octahedron, in a manner analogous to tripodal borate ligands such as [Tp $],{ }^{14}\left[\mathrm{PhTt}^{\mathrm{R}}\right],{ }^{15}$ and $\left[\mathrm{PhBP}_{3}\right]^{2}$ The propensity of the $\left[{ }^{\mathrm{Si}} \mathrm{NP}_{2}\right]$ ligand to enforce such a distorted tetrahedral geometry likely stems from the tight chelate that arises from having both phosphine arms branch from a common silyl linker. As expected, a space-filling model of 3 (Fig. 3c) reveals significantly less steric protection about the halide binding site in comparison to $\mathbf{2 b}$. Additionally, it is interesting to note that for both $\mathbf{3}$ and $\mathbf{4 b}$, the 2,6-diisopropylanilide donor lies perpendicular to the Co-I vector rather than canted as in $\mathbf{2 b}$, likely because the environment is less sterically demanding. Given this binding geometry and the additional presence of the arylamido donor ligand, we had expected that cobalt complexes $\mathbf{4 a}$ and $\mathbf{4 b}$ might adopt low spin configurations, akin to certain $\left[\mathrm{PhBP}_{3}\right] \mathrm{Co}^{\mathrm{II}}-\mathrm{X}$ systems we have previously described. ${ }^{2}$ However, both $\mathbf{4 a}$ and $\mathbf{4 b}$ are high spin. These assignments are consistent with their room temperature Evans method determinations $\left(\mu_{\mathrm{eff}}=3.7 \mu_{\mathrm{B}}\right.$ for $\mathbf{4 a}, 4.0$ $\mu_{\mathrm{B}}$ for $\mathbf{4 b}$ ) and the elongated $\mathrm{Co}-\mathrm{P}$ and $\mathrm{Co}-\mathrm{I}$ bond distances revealed by the $100 \mathrm{~K} \mathrm{X}$-ray structure of $\mathbf{4 b}$. In a comparative context, these data continue to underscore how unusual the electronic properties of the parent $\left[\mathrm{PhBP}_{3}\right]$ ligand are compared with structurally related tripodal ligands. ${ }^{2}$

Complexes $\mathbf{3}$ and $\mathbf{4 a}$ were also examined by cyclic voltammetry (see ESI for voltammograms of each complex). The CV of $\mathbf{3}$ does not show any reversible redox events. An irreversible reduction peak beginning at $-2.1 \mathrm{~V}$ is evident, as is an oxidative wave at 

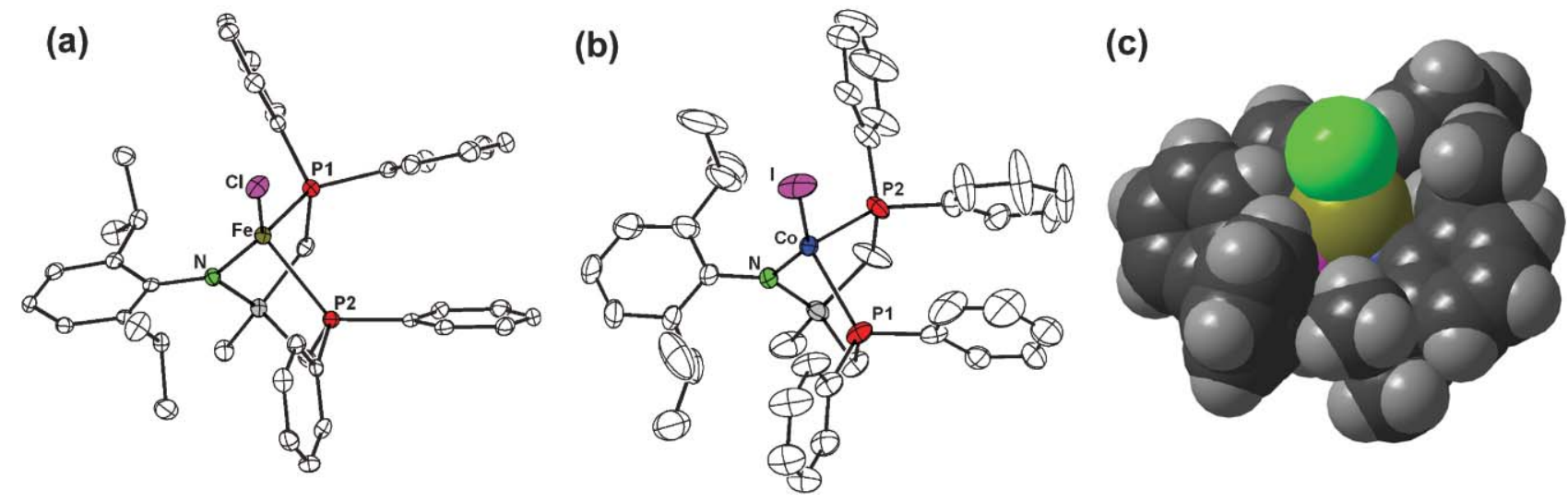

Fig. 3 Structural representations of (a) $\left[{ }^{\mathrm{Si}} \mathrm{NP}_{2}\right] \mathrm{FeCl}$ (3) and (b) $\left[{ }^{\mathrm{Si}} \mathrm{NP}_{2}\right] \mathrm{CoI}$ (4b) with thermal ellipsoids at $50 \%$ probability, and (c) a space-filling representation of $\left[{ }^{\mathrm{Si}} \mathrm{NP}_{2}\right] \mathrm{FeCl}$. (a) Hydrogen atoms and a molecule of benzene have been omitted for clarity. Selected bond distances $(\AA)$ and angles $\left({ }^{\circ}\right)$ : FeN 1.953(2), Fe-P1 2.4180(8), Fe-P2 2.4903(8), Fe-Cl 2.2418(8), N-Fe-P1 89.76(5), N-Fe-P2 90.91(6), N-Fe-Cl 140.03(6), P1-Fe-P2 94.98(3), P1-Fe-Cl 118.30(3), $\mathrm{P} 2-\mathrm{Fe}-\mathrm{Cl} 112.48(3)$. (b) Hydrogen atoms and a molecule of diethyl ether have been omitted for clarity. Selected bond distances ( $\AA$ ) and angles ${ }^{\circ}$ ): Co-N 1.910(3), Co-P1 2.3849(9), Co-P2 2.3731(8), Co-I 2.5258(5), N-Co-P1 89.78(8), N-Co-P2 90.29(9), N-Co-I 143.57(8), P1-Co-P2 93.44(3), P1Co-I 115.61(3), P2-Co-I 112.33(3).

$+0.24 \mathrm{~V}$. A smaller reduction wave centered at $-0.63 \mathrm{~V}$ grows in as a result of scanning through the oxidation process at $+0.24 \mathrm{~V}$. The CV data for $\mathbf{4 a}$ show a quasi-reversible wave centered at $-0.17 \mathrm{~V}$, corresponding to a $\mathrm{Co}^{\mathrm{II} / \mathrm{II}}$ oxidation event. Additionally, there is an irreversible reduction wave at $-1.4 \mathrm{~V}$ and a smaller irreversible oxidative wave at $-0.40 \mathrm{~V}$. The putative $\mathrm{Co}^{\mathrm{I} / 1}$ reduction event occurs at a potential $c a$. $0.7 \mathrm{~V}$ more positive for compound $\mathbf{4 a}$ compared with $\mathbf{2 a}$.

In summary, we have introduced two new amido-polyphosphine ligands and thoroughly characterized divalent iron and cobalt halide complexes of each system. The $\left[{ }^{\mathrm{Si}} \mathrm{NP}_{3}\right]$ and $\left[{ }^{\mathrm{Si}} \mathrm{NP}_{2}\right]$ ligands are related in that each is monoanionic and strongly electron-releasing. However, whereas the $\left[{ }^{\mathrm{Si}} \mathrm{NP}_{2}\right]$ ligand is predisposed to bind in a tridentate, tripodal fashion, the $\left[{ }^{\mathrm{Si}} \mathrm{NP}_{3}\right]$ ligand can adopt both tridentate and tetradentate binding modes depending on the electronic requirements of the metal center. The $\left[{ }^{\mathrm{Si}} \mathrm{NP}_{2}\right]$ ligand enforces a highly distorted geometry reminiscent of other tripodal ligands such as $[\mathrm{Tp}]$ and $\left[\mathrm{PhBP}_{3}\right]$. We are currently exploring the affinity of these systems for binding $\mathrm{N}_{2}$ and other $\pi$-acidic substrates under reducing conditions.

We acknowledge the NIH (GM 070757 to JCP) for financial support of this work. MTW is grateful to the Moore Foundation for a graduate fellowship. Neal Mankad and Larry Henling provided crystallographic assistance.

\section{Notes and references}

\$ Details of the X-ray diffraction studies: $1, \mathrm{C}_{56.5} \mathrm{H}_{61} \mathrm{ClFeNP}_{3} \mathrm{Si}$ : triclinic, space group $P-1, a=10.8604(17) \AA, b=20.831(3) \AA, c=23.586(4) \AA$, $\alpha=72.318(3)^{\circ}, \beta=83.313(3)^{\circ}, \gamma=89.880(3)^{\circ}, V=5046.3(14) \AA^{3}, Z=4$, $\mu(\mathrm{Mo}-\mathrm{K} \alpha)=0.509 \mathrm{~mm}^{-1}$. 19505 total reflections, 14316 independent $\left(R_{\text {int }}=8.01 \%\right)$ with $I>2 \sigma(I) ; \mathbf{2 a}, \mathrm{C}_{51} \mathrm{H}_{52} \mathrm{ClCoNP}_{3} \mathrm{Si}$ : triclinic, space group $P-1, a=12.8058(15) \AA, b=17.612(2) \AA, c=20.505(3) \AA, \alpha=93.701(4)^{\circ}$, $\beta=91.736(4)^{\circ}, \gamma=103.463(4)^{\circ}, V=4483.4(10) \AA^{3}, Z=4, \mu(\mathrm{Mo}-$ $\mathrm{K} \alpha)=0.613 \mathrm{~mm}^{-1} .17435$ total reflections, 9939 independent $\left(R_{\text {int }}=13.19 \%\right)$ with $I>2 \sigma(I) ; \mathbf{2 b}, \mathrm{C}_{63} \mathrm{H}_{64} \mathrm{CoINP}_{3} \mathrm{Si}$ : monoclinic, space group $P 2_{1} / c, a=13.0701(10) \AA, b=19.1387(15) \AA, c=22.1493(16) \AA$, $\beta=102.943(3)^{\circ}, V=5399.8(7) \AA^{3}, Z=4, \mu(\mathrm{Mo}-\mathrm{K} \alpha)=1.042 \mathrm{~mm}^{-1}$. 44992 total reflections, 10823 independent $\left(R_{\text {int }}=16.66 \%\right)$ with $I>2 \sigma(I)$; 3, $\mathrm{C}_{45} \mathrm{H}_{50} \mathrm{ClFeNP}_{2} \mathrm{Si}$ : monoclinic, space group $P 2_{1} / n, a=9.793(3) \AA$, $b=9.371(3) \AA, c=44.610(12) \AA, \beta=94.581(4)^{\circ}, V=4080.9(19) \AA^{3}, Z=4$, $\mu(\mathrm{Mo}-\mathrm{K} \alpha)=0.575 \mathrm{~mm}^{-1}$. 34419 total reflections, 8553 independent
$\left(R_{\text {int }}=7.69 \%\right)$ with $I>2 \sigma(I) ; \mathbf{4 b}, \mathrm{C}_{43} \mathrm{H}_{54} \mathrm{CoINOP}_{2} \mathrm{Si}$ : monoclinic, space group $P 2_{1} / c, a=11.6071(8) \AA, b=21.6762(15) \AA, c=16.8895(12) \AA$, $\beta=92.988(2)^{\circ}, V=4243.6(5) \AA^{3}, Z=4, \mu(\mathrm{Mo}-\mathrm{K} \alpha)=1.268 \mathrm{~mm}^{-1} .77696$ total reflections, 14707 independent $\left(R_{\text {int }}=7.91 \%\right)$ with $I>2 \sigma(I)$. CCDC 289249-289252. For crystallographic data in CIF or other electronic format see DOI: $10.1039 / \mathrm{b} 516046 \mathrm{~d}$

1 T. A. Betley and J. C. Peters, J. Am. Chem. Soc., 2004, 126, 6252; S. D. Brown, T. A. Betley and J. C. Peters, J. Am. Chem. Soc., 2003, 125, 322; D. M. Jenkins, T. A. Betley and J. C. Peters, J. Am. Chem. Soc., 2002, 124, 11238.

2 D. M. Jenkins, A. J. Di Bilio, M. J. Allen, T. A. Betley and J. C. Peters, J. Am. Chem. Soc., 2002, 124, 15336; D. M. Jenkins and J. C. Peters, J. Am. Chem. Soc., 2005, 127, 7148.

3 D. M. Jenkins and J. C. Peters, J. Am. Chem. Soc., 2003, 125, 11162.

4 M. D. Fryzuk and P. A. Macneil, J. Am. Chem. Soc., 1981, 103, 3592.

5 M. D. Fryzuk, J. B. Love and S. J. Rettig, Chem. Commun., 1996, 2783; M. D. Fryzuk, S. A. Johnson and S. J. Rettig, J. Am. Chem. Soc., 1998, 120, 11024

6 M. D. Fryzuk, Can. J. Chem., 1992, 70, 2839; M. D. Fryzuk, J. B. Love, S. J. Rettig and V. G. Young, Science, 1997, 275, 1445.

7 M. D. Fryzuk, D. B. Leznoff, E. S. F. Ma, S. J. Rettig and V. G. Young, Organometallics, 1998, 17, 2313; M. D. Fryzuk, D. B. Leznoff, R. C. Thompson and S. J. Rettig, J. Am. Chem. Soc., 1998, 120, 10126.

8 M. Ingleson, H. Fan, M. Pink, J. Tomaszewski and K. G. Caulton, J. Am. Chem. Soc., 2006, 128, 1804.

9 O. V. Ozerov, C. Y. Guo, V. A. Papkov and B. M. Foxman, J. Am. Chem. Soc., 2004, 126, 4792; A. Walstrom, M. Pink, X. F. Yang, J. Tomaszewski, M. H. Baik and K. G. Caulton, J. Am. Chem. Soc., 2005, 127, 5330.

10 P. Stoppioni, F. Mani and L. Sacconi, Inorg. Chim. Acta, 1974, 11, 227; T. A. George, D. J. Rose, Y. D. Chang, Q. Chen and J. Zubieta, Inorg. Chem., 1995, 34, 1295.

11 D. F. Evans, J. Chem. Soc., 1959, 2003; S. K. Sur, J. Magn. Reson., 1989, 82, 169.

12 Although $\left[{ }^{\mathrm{Si}} \mathrm{NP}_{3}\right] \mathrm{CoI}$ (2b) was more readily crystallized than its chloride congener $\mathbf{2} \mathbf{a}$, analytically pure bulk samples of $\mathbf{2 a}$ were more readily obtained.

13 For a similar approach to enforcing a fac-only geometry, $c f$. the diamido-pyridyl ligands developed by Gade; L. H. Gade, Chem. Commun., 2000, 173; P. Mehrkhodavandi, P. J. Bonitatebus and R. R. Schrock, J. Am. Chem. Soc., 2000, 122, 7841.

14 S. Trofimenko, Scorpionates: the coordination chemistry of polypyrazolyl borates, Imperial College Press: London, 1999.

15 P. J. Schebler, B. S. Mandimutsira, C. G. Riordan, L. M. Liable-Sands, C. D. Incarvito and A. L. Rheingold, J. Am. Chem. Soc., 2001, 123, 331; P. H. Ge, B. S. Haggerty, A. L. Rheingold and C. G. Riordan, J. Am. Chem. Soc., 1994, 116, 8406. 